\title{
Perspectives of 2D and 3D mapping of atmospheric pollutants over urban areas by means of airborne DOAS spectrometers
}

\author{
Giorgio Giovanelli $\left({ }^{1}\right)$, Elisa Palazzi $\left({ }^{1}\right)$, Andrea Petritoli $\left({ }^{1}\right)$, Daniele Bortoli $\left({ }^{1}\right)\left({ }^{2}\right)$, \\ Ivan Kostadinov $\left({ }^{1}\right)\left({ }^{3}\right)$, Federico Margelli $\left({ }^{1}\right)$, Simonetta Pagnutti $\left({ }^{1}\right)$, Margherita Premuda $\left({ }^{4}\right)$, \\ Fabrizio Ravegnani $\left.{ }^{(}\right)$and Giuliano Trivellone $\left(^{1}\right)$ \\ (') Istituto di Scienze dell'Atmosfera e del Clima (ISAC), CNR, Bologna, Italy \\ (2) Geophysics Centre of Évora - University of Évora (CGE-UE), Évora, Portugal \\ $\left(^{3}\right)$ Solar-Terrestrial Influences Laboratory (STIL), Bulgarian Academy of Science, Stara Zagora, Bulgaria \\ $\left({ }^{4}\right)$ ENEA, Divisione Fisica Applicata, Centro Ricerche Bologna, Italy
}

\begin{abstract}
In the field of air quality control, optical remote sensing systems can measure the spatial distribution of gas pollutants, offering numerous advantages over conventional networks of in situ analysers. We propose some innovative solutions in the field of DOAS (Differential Optical Absorption Spectroscopy) remote systems, utilizing diffuse solar light as the radiation source. We examine the numerous potentialities of minor gas slant column calculations, applying the «off-axis» methodology for collecting the diffuse solar radiation. One of these particular approaches, using measurements along horizontal paths, has already been tested with the spectrometer installed on board the Geophysica aircraft during stratospheric flights up to altitudes of $20 \mathrm{~km}$. The theoretical basis of these new measurement techniques using DOAS remote sensing systems are delineated to assess whether low altitude flights can provide 2D and 3D pollution tomography over metropolitan areas. The 2D or 3D trace gas total column mapping could be used to investigate: i) transport and dispersion phenomena of air pollution, ii) photochemical process rates, iii) gas plume tomography, iv) minor gas vertical profiles into the Planetary Boundary Layer and v) minor gas flux divergence over a large area.
\end{abstract}

Key words DOAS applications in urban areas - atmospheric pollutants tomography - aircraft measurements of atmospheric trace gases

\section{Introduction}

The growth in human activity over the last century has led to an enormous increase in en-

Mailing address. Dr. Giorgio Giovanelli, Istituto di Scienze dell'Atmosfera e del Clima (ISAC), CNR, Area della Ricerca CNR, Via Gobetti 101, 40129 Bologna, Italy; e-mail: G.Giovanelli@isac.cnr.it ergy consumption with the consequent emission of substances in quantities greater than those which the atmosphere can absorb.

In metropolitan areas wide-gridded networks of in situ analysers are normally used for the continuous recording of gas pollutant concentrations. These networks are, however, expensive and the single point measurements are often insufficient to characterise the photochemical and transport phenomena even over small areas. Remote sensing systems can play an important role, representing a good compromise between spatial resolution and sensitivity of the measurements, providing more extensive coverage. In particular, DOAS (Differential 
Optical Absorption Spectroscopy) remote sensors open up new perspectives in the field of pollutant analysis and control such as, for example, the monitoring of a large number of gases simultaneously with a single instrument and a better characterisation of the area examined through the integration of gas concentrations over the entire optical path of the measurements.

In the field of air quality control and monitoring, one of the current, most important problems is how to measure the three-dimensional distributions of airborne pollutants in the lower atmospheric layers within the Planetary Boundary Layer (PBL) over urban and industrial areas, and in a systematic way. Over the past few decades diffusion and chemical modeling techniques have been developed which allow calculation of 3D trace gas distributions with a spatial resolution of less than $1000 \mathrm{~m}$ and the detailed control of air quality in urban and industrial areas has become a fundamental aim for keeping environmental health within acceptable limits (von Kuhlmann et al., 2003).

Passive remote sensing systems, such as spectrometers used in conventional modes, can at best calculate 2D maps of columnar abundances of the gaseous species under investigation integrated over the given measurement path (for example, from the ground to the flight altitude with a spectrometer, on board the aircraft, making «nadir» measurements). Even gas profiles obtained using inversion methods (Petritoli et al., 2002a) from a series of zenithsky DOAS observations during twilight cannot supply the vertical and temporal resolution necessary for Chemical Transport Models (CTMs) validation (Finzi et al., 2001).

Airborne Differential-LIDAR (Browell et al., 1998) could, theoretically, provide 3D mapping of gases but, besides the «eye-safe» power limits of the technique (several tens of $\mathrm{mW}$ ), there are obvious economic and technical difficulties in reaching a payload compatible with the requirements of a local service carrying out atmospheric analyses and air quality control.

Thus, it would seem that there are, at present, no economically accessible remote sensing techniques available for systematic 3D mapping of pollutants in the lower atmosphere which could be utilized in widescale national air quality programs and surveys.

On the other hand, there is a field to be explored with great attention: that of diffuse solar light measurements, with UV-VIS or IR spectrometers utilised in non-conventional configurations, defined as «off-axis» methods, to distinguish them from the classic nadir and zenith observations. In this work we will examine the response of a spectrometric system with zenithal movement of the input optics and estimate the diffuse radiation flux values, collected by the input optics of the spectrometer, as a function of the angle from the zenith. The final purpose of these efforts is to formulate a new method for the quasi-real-time reconstruction of the $2 \mathrm{D}$ and $3 \mathrm{D}$ trace gas distributions in the atmospheric layers closest to ground level. For example, by flying at an altitude between 2000 and 4000 m, it will be possible to measure the vertical distribution of gaseous pollutants, such as $\mathrm{NO}_{2}, \mathrm{SO}_{2}, \mathrm{O}_{3}, \mathrm{HNO}_{2}$, benzene, formaldehyde, toluene and xylene within the PBL.

\section{DOAS methodology for pollutant gas measurements in urban areas}

The DOAS methodology was first introduced by Noxon (1975) in the early 70's for measurements of total atmospheric gas columns, using diffuse solar light along the vertical path as the source of radiation (passive mode). The use of this technique rapidly became widespread in ground-based climatic stations and in airborne (Giovanelli et al., 2000) and satellite systems (Geophysica, ER2 stratospheric aircraft, Gome and Sciamashy) to study the climatic distribution of minor stratospheric gases and ozone loss phenomena.

Later, Platt and Perner (1980) began to use the method to measure optical depths of trace gases along horizontal trajectories, using a UV lamp as an artificial radiation source (active mode). More recently, the technique has also offered a method for environmental monitoring in urban and industrial areas (Brocco et al., 1992; Edner et al., 1993; Evangelisti et al., 1995; Ravegnani et al., 1997). In fact, the DOAS methodology permits the simultaneous measurement with 
a single instrument of the concentrations of various gases with distinct absorption bands in the UV/VIS spectral range (conventional analysers are gas-specific) such as $\mathrm{O}_{3}, \mathrm{NO}_{2}, \mathrm{SO}_{2}$, formaldehyde $\mathrm{CH}_{2} \mathrm{O}$ (Platt and Perner, 1980), nitrous acid $\mathrm{HNO}_{2}$ (Platt et al., 1980), the nitrate radical $\mathrm{NO}_{3}$ (Platt et al., 1981), benzene $\mathrm{C}_{6} \mathrm{H}_{6}$, toluene $\mathrm{C}_{7} \mathrm{H}_{8}$ and other hydrocarbons of general formula $\mathrm{C}_{x} \mathrm{H}_{y}$.

With the DOAS methodology, gas concentrations are retrieved from their absorption characteristics in the UV-VIS spectrum. The method is based on the Lambert-Beer Law in its differential form (the low frequency spectra are subtracted from the original ones)

$$
\ln \left(\frac{I_{0}(\lambda)}{I(\lambda)}\right)-\overline{\ln \left(\frac{I_{0}(\lambda)}{I(\lambda)}\right)}=\sum_{g=1}^{n} \Delta \sigma_{g}(\lambda) C_{g} L
$$

where $I_{0}(\lambda)$ is the reference spectrum, i.e. the radiance outside the atmosphere, $I(\lambda)$ is the radiation intensity after passing through a layer of thickness $L, \Delta \sigma_{g}$ is the Differential absorption Cross Section (DCS) of the $g$ th gas at the wavelength $\lambda$, obtained by subtracting the low frequency spectrum from its Absolute absorption Cross Section (ACS). The summation is over all absorbers in the examined spectral range. The result of the equation gives the integral of the $g$ th gas concentration $(C g)$ along the measurement path $(L)$. A more detailed description of DOAS methodology is available in Solomon et al. (1987), Giovanelli et al. (1990).

At the ISAC-CNR Institute various types of instruments, known as GASCOD (Gas Absorption Spectrometers Correlating Optical Differences), have been developed for the estimation of gas column quantities and profiles from zenith diffuse solar radiation measurements at groundbased stations. An airborne multi-input version (GASCOD/A $4 \pi$ ) has been developed for measurement of both gas total columns and actinic flux on board the Geophysica-M55 stratospheric aircraft, together with other remote sensing and in situ equipment. The GASCOD/A4 $\pi$ operated successfully during the APE-THESEO (Seychelles) and APE-GAIA (Ushuaia, Argentina) campaigns in 1999 (Petritoli et al., 1999) and, more recently, in a validation program of the ENVISAT satellite (Kostadinov et al., 2006).
A modified version of this spectrometer has also been used to measure pollution at ground level in urban areas along horizontal paths, employing a xenon lamp as radiation source. Starting from this latest prototype, an Italian company has developed a commercial version for installation in networks of in situ analysers for atmospheric analyses and air quality control in urban and industrial areas.

In conventional ground-based networks active DOAS systems can be configured as bistatic, where the measurement path length $L$ is defined by the instrument (receiver) and by the projector creating the beam (emitter), or monostatic (fig. 1), where the emitter and the receiver are deployed at the same site with the use of retroreflectors for probing of the same optical path examined in bistatic mode, but doubled.

Although the most immediate use of DOAS instrumentation is air quality control in an environmental monitoring network, its potential can be fully exploited when used in less conventional ways. There are innovations both in the measurement techniques and in the subsequent data analysis. Often these two aspects become so intertwined that it becomes difficult to draw a distinction.

As mentioned above, the DOAS methodology was first used to obtain slant columns of minor gases in the stratosphere by processing zenith diffuse solar radiation measurements from ground-based stations. The subsequent «off-axis» approach was a logical extension deriving from the need to detect the presence of gases, in the stratosphere, with low absorption coefficients and low concentrations (e.g., total $\mathrm{O}_{3}$ column, nitro-

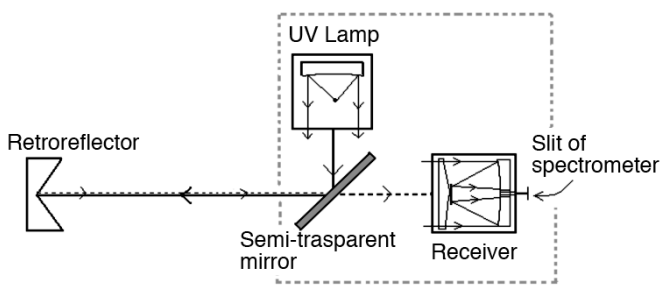

Fig. 1. Monostatic configuration of a DOAS spectrometer for air pollution measurement. 
gen oxides, chlorine and bromine during ozone depletion processes) (Giovanelli et al., 2001).

The most recent application of the off-axis method is the «horizontal view looking» technique, which allows quasi in situ trace gas concentration measurements (Petritoli et al., 2002b).

Its application in «horizontal DOAS tomography» represents an important methodological innovation in the interpretation of DOAS data to obtain 2D and 3D pollutant distributions over a limited area (Hashmonay et al., 1999; Vogel et al., 2000).

However, DOAS tomography in the groundbased configuration, recently proposed by the IUP (Institut für UmweltPhysik) of the University of Heidelberg, requires the use of a significant number of spectrometers and retro-reflectors to obtain 2D and 3D pollutant mapping. In the 1980s a similar approach was attempted to obtain the bidimensional structure of a stack plume in terms of the optical depth of $\mathrm{SO}_{2}$ using off-axis measurements with a Mask Correlation remote sensor (Giovanelli et al., 1979). The reconstruction of plume structure was obtained by making a series of azimuthal scans of diffuse solar radiation downwind from the stack, and for each of these zenithal scans were also made. Various Eu- ropean research groups, besides our own, are beginning to show increasing interest in off-axis measurements both in ground-based and airborne configurations, derived from DOAS methods, to obtain 2D or 3D air pollutant mapping inside the PBL in urban and industrial areas.

\section{DOAS measurements with vertical view looking configurations}

Usually, estimation of the columnar abundances of minor atmospheric gases from measurements of solar diffuse radiation (at zenith or in other directions) is quite complex, since it requires the derivation of a suitable Atmospheric Transfer Equation (ATE). Processing of DOAS measurements in the vertical view looking configuration, includes the following steps:

i) Derivation of the ATE, which provides the best description of the atmospheric transfer for diffuse solar radiance measurements along the vertical axis.

ii) Measurements and retrieval of the slant column of the given gas, using multiple linear regression or Single Value Decomposition (SVD). The slant column is the integral of the gas con-

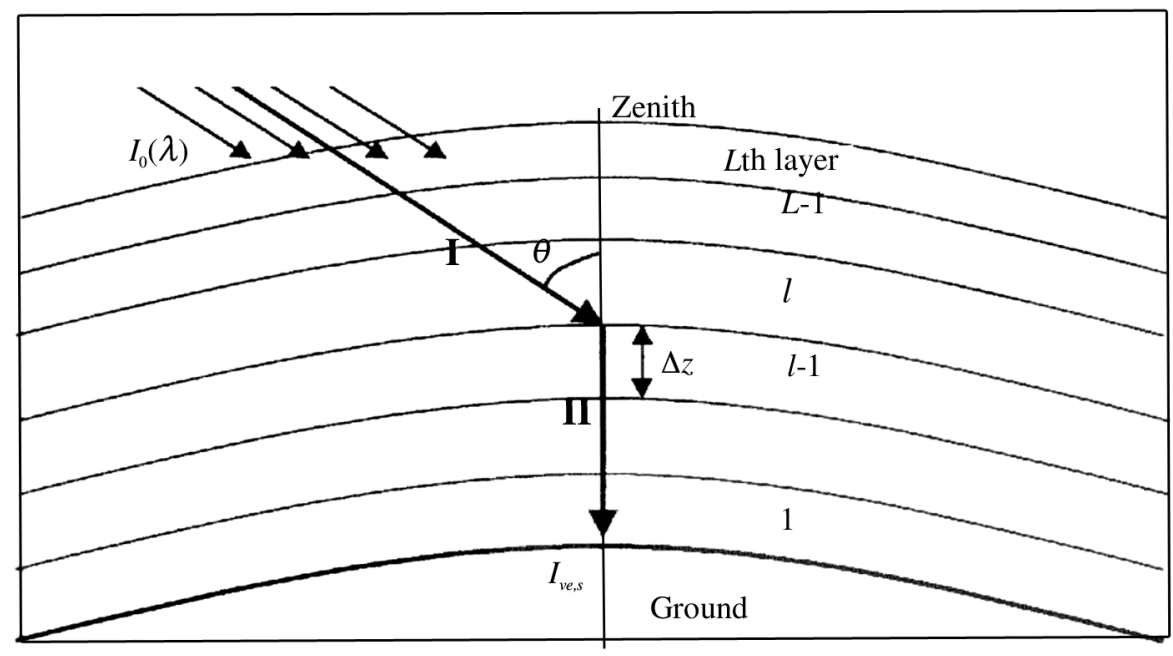

Fig. 2. Schematic diagram of path lengths in the atmospheric transfer model of DOAS zenith solar light measurement. 


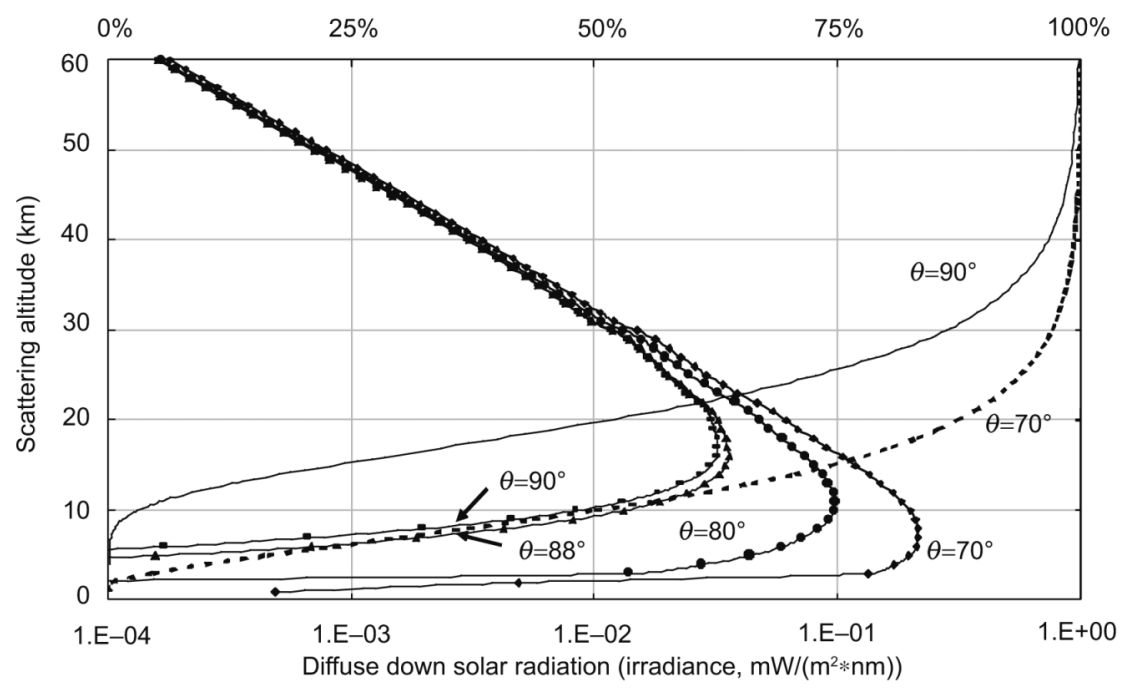

Fig. 3. Computed intensity of downward diffuse solar radiation as function of the scattering point along a vertical path. Four curves are plotted for different SZA, considering $\lambda=330 \mathrm{~nm}$ and Vis $=5 \mathrm{~km}$. The accumulated probability trends, respectively due to the $\theta=70^{\circ}$ irradiance curve and to the $\theta=90^{\circ}$ irradiance curve are also shown.

centration along the atmospheric slant paths defined with respect to the Solar Zenith Angle (SZA) $\theta$ (fig. 2).

iii) Calculation of the Intensity Weighted Optical Path (IWOP), which correlates the optical trajectory of the diffuse radiation with the radiation intensity along that trajectory.

iv) Calculation of the «air mass» or «enhancement» factor (AMF), defined as the ratio between the slant column and the vertical column, defined as the integral of the gas concentration along the vertical path.

In the ATE model developed in our group (Giovanelli et al., 1990), the atmosphere is subdivided into $L=120$ spherical layers, each $\Delta z=1$ $\mathrm{km}$ thick (fig. 2) and summation is used instead of the integral.

The irradiance scattered along the vertical path and collected on the ground can be represented by the following equation:

$$
I_{v e, s}(\lambda)=\sum_{l=1}^{L} I_{l, s}(\lambda)
$$

where $l=1,2, \ldots, L$ denotes the $l$ th scattering level and each $I_{l, s}(\lambda)$ is the contribution of the radiation flux towards the ground, produced by scat- tering in the $l$ th layer and defined by the equation

$$
I_{l, s}(\lambda)=I_{0}(\lambda) \cdot \sigma_{0}(\lambda) \cdot f(\theta) \cdot N_{0} \cdot \Delta z \cdot\left[A_{V e}\right] \cdot\left[A_{S l}\right]
$$

where $I_{0}(\lambda)$ has the same meaning defined in (2.1), $\sigma_{0}(\lambda)$ represents the scattering cross section of air molecules, $f(\theta)$ is the molecular scattering function, derived from the Rayleigh scattering formula, which defines the fraction of the scattered radiation flux in the ground direction, versus the diurnal variation of $\operatorname{SZA} \theta, N_{0}$ is the average air molecule density and $\Delta z$ is $1 \mathrm{~km}$. The bracketed terms $\left[A_{V e}\right]$ and $\left[A_{S l}\right]$ are, respectively, the absorption along the vertical path and along the slant path. $\left[A_{V e}\right]$ is defined as follows:

$$
\left[A_{V e}\right]=\exp -\left[\sum_{i=1}^{l} \cdot\left(\sum_{g=0}^{n} \sigma_{g}(\lambda) \cdot N_{i, g}(\lambda)\right) \cdot(\Delta z)_{i}\right]
$$

where $i=1,2, \ldots, l$ is the $i$ th vertical layer, $\sigma_{g}(\lambda)$ is the absorption cross section of the $g$ th absorber with $g=0,1,2, \ldots, n$ (the 0 subscript indicates the molecular cross section for Rayleigh scattering), $N_{i, g}(\lambda)$ is the average molecular 
density of the $g$ th absorber in the $i$ th layer. $\left[A_{S l}\right]$ is defined by the equation

$$
\begin{aligned}
& {\left[A_{S l}\right]=\exp -\left[\sum_{j=(z+1)}^{L} \cdot\left(\sum_{g=0}^{n} \sigma_{g}(\lambda) \cdot N_{j, g}(\lambda) \cdot \mu_{g}(\theta)\right)\right.} \\
& \left.\cdot(\Delta s(\theta))_{j}\right]
\end{aligned}
$$

where $j=(z+1),(z+2), \ldots, L$ is the $j$ th slant layer with $z$ the scattering level, $\sigma_{g}(\lambda)$ and $N_{j, g}(\lambda)$ have the same meaning defined in (3.3), $\mu_{g}(\theta)$ is the $g$ th absorber's air mass factor, including Mie, Rayleigh and Ring AMFs, computed for the most probable slant path obtained through computation of the IWOP.

By applying this atmospheric transfer equation it is possible to compute, for different wavelengths, the downward scattered radiation received by the spectrometer input optics, as a function of both the height at which the scattering occurs along the vertical direction and the varying SZA. In fig. 3 the flux of zenith diffuse solar radiation is plotted for different $\theta$ values and for $\lambda=330 \mathrm{~nm}$. It is interesting to observe how, in these irradiance curves, the level of the maximum scattering value increases as a function of higher
SZAs. This can also be observed in the two accumulated probability curves of irradiance.

\section{DOAS off-axis measurements}

In order to increase the gas optical depth to measure compounds that do not show strong absorptions in the UV-VIS range, measurements are performed along oblique atmospheric paths, generically called off-axis, by rotating the optical input of the spectrometer from the zenith.

The off-axis measurements are divided into several configurations according to the field of application and the various ATEs. The latter have to be developed for an adequate interpretation of the flux of diffuse solar radiation along the particular off-axis direction being observed. The off-axis measurements are named according to the particular angle being examined: if the Line Of Sight (LOS) of the input optics $(\varphi)$ changes from $90^{\circ}$ towards $0^{\circ}$, the measurement method is known as oblique-up view looking, whose ATE is briefly described below. There are two other configurations: «horizontal view looking» and «oblique-down view looking». The former is briefly described in the next para-

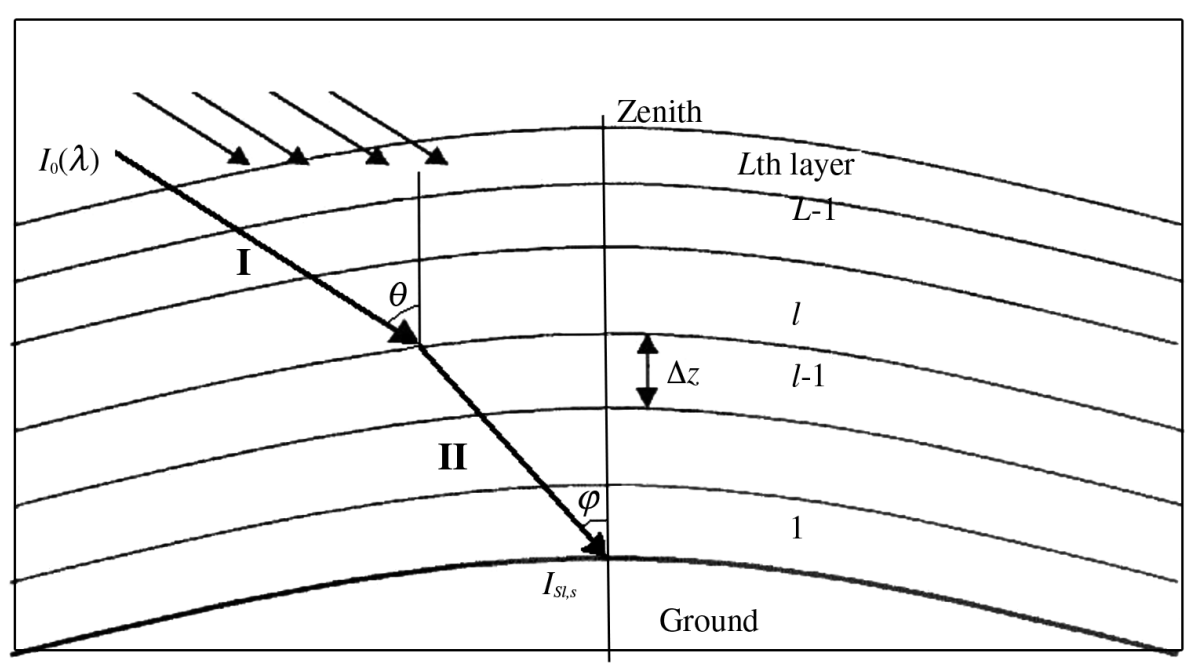

Fig. 4. Schematic diagram of path lengths in the atmospheric transfer model of DOAS solar light measurement at oblique-up view looking. 
graph and the latter is still the subject of study and experimental verification.

The oblique-up view looking method is used to detect thin optical depth stratospheric minor gases, such as $\mathrm{O}_{3}$ and $\mathrm{NO}_{2}$ in polar region during ozone depletion and denitrification periods and halogen compounds ( $\mathrm{BrO}$ and OClO), (Giovanelli et al., 2001).

By analogy with equations presented in the previous section, the ATE can be derived for oblique paths. The irradiance scattered along the oblique path and collected at ground level can be represented by the following equation:

$$
I_{O b, s}(\lambda)=\sum_{l=1}^{L} I_{O b, s, l}(\lambda)
$$

where the «Ob» subscript defines the paths of the light collected by the input optics, which should not be confused with the slant paths of the solar radiation before scattering which are defined by the subscript «Sl» (fig. 4) and each $I_{O b, s, l}(\lambda)$ is the contribution of the radiation flux towards the ground, produced by scattering in the $l$ th layer and is defined by the equation

$$
\begin{aligned}
& I_{O b, s, l}(\lambda)=I_{0}(\lambda) \cdot \sigma_{0}(\lambda) \cdot f(\theta-\varphi) \cdot N_{0} \cdot \Delta_{o b}(\varphi) \\
& \cdot\left[A_{O b}\right] \cdot\left[A_{S l}\right]
\end{aligned}
$$

where $I_{0}(\lambda), s_{0}(\lambda), f(\theta-\varphi), N_{0}$ have the same meaning defined in the previous equations, $\varphi$ indicates the spectrometer's LOS, $\Delta_{O b}(\varphi)$ is the thickness of the layer in the LOS direction and the bracketed terms $\left[A_{O b}\right]$ and $\left[A_{S l}\right]$ are, respectively, the absorption along the oblique path and the slant path.

As for the case of vertical view looking configuration, it is possible to evaluate the trends of the scattered radiation received by the spectrometer input optics as a function of both the height at which the scattering occurs along the oblique direction and the varying SZA.

\section{DOAS measurements with horizontal view looking configuration}

Measurements with DOAS systems using the horizontal view looking configuration present some interesting fields of application both in climatic studies as well as in air pollution control.

Regarding climatic studies in the stratosphere, our group has recently developed a novel application of horizontal view looking, using a UV-VIS spectrometer on board the Geophysica aircraft (Petritoli et al., 2002b). The measurement geometry is very similar to the limb-scanning mode used so far by satellite borne instruments to measure atmospheric radiance (i.e., in the IR spectral region by MIPAS-E and in the UV-VIS region by Sciamachy for the DOAS methodology, and both together on board the ENVISAT satellite). The scattered solar radiation collected along a horizontal trajectory is compared, in terms of the Lambert-Beer Law, with the scattered solar radiation collected along a zenithal path (fig. 5). The differential slant column signal is composed of two contributions from the $V$ and $H_{0,4}$ path (fig. 5). Radiative transfer calculations show that $V$ is negligible with respect to $H_{0,4}$ so that by calculating $H_{0,4}$ with the model it is possible to obtain the average concentration of the trace gas along the horizontal direction at flight level. This method, which allows quasi in situ gas concentration estimates, combines vertical and horizontal measurements and is known as ACILA (Average Concentration Inside the Layer near the Aircraft). $H_{0,4}$ is a function of the spectral interval we are measuring and of the trace gas we are interested in. For ozone at $330 \mathrm{~nm}$ at an average flight altitude of $20 \mathrm{~km}, H_{0,4}$ is about $50-70 \mathrm{~km}$. The method has already been tested with measurements carried out in the frame of APE-GAIA campaign (15 September to 14 October 1999), during which the M55 Geophysica aircraft flew over the Antarctic Peninsula (Carli et al., 2000).

In the field of air pollution control the question is whether a source of artificial radiation is indispensable for horizontal measurements or whether it is possible to operate with diffuse solar radiation, thus allowing a greater degree of freedom in the measurements. The latter hypothesis is innovative and opens up fields of application previously considered impossible, or extremely onerous due to the nature of the equipment required.

The enormous potential of these near ground-level horizontal measurements of dif- 


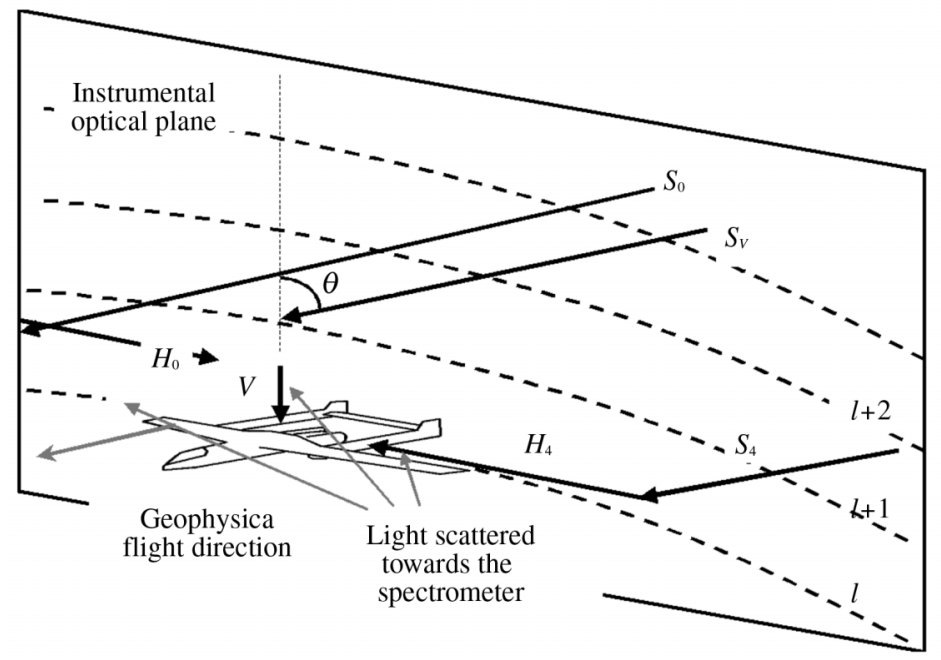

Fig. 5. Measurement geometry used to retrieve ACILA. When spectra from the zenith are used as reference in the DOAS calculation the $S_{V}$ path and $S_{0,4}$ paths cancel out and what remain in the signal is due to the absorption along $V$ and $H_{0,4}$. Model calculations give $H_{0,4}>>V$ so that $V$ can be neglected.

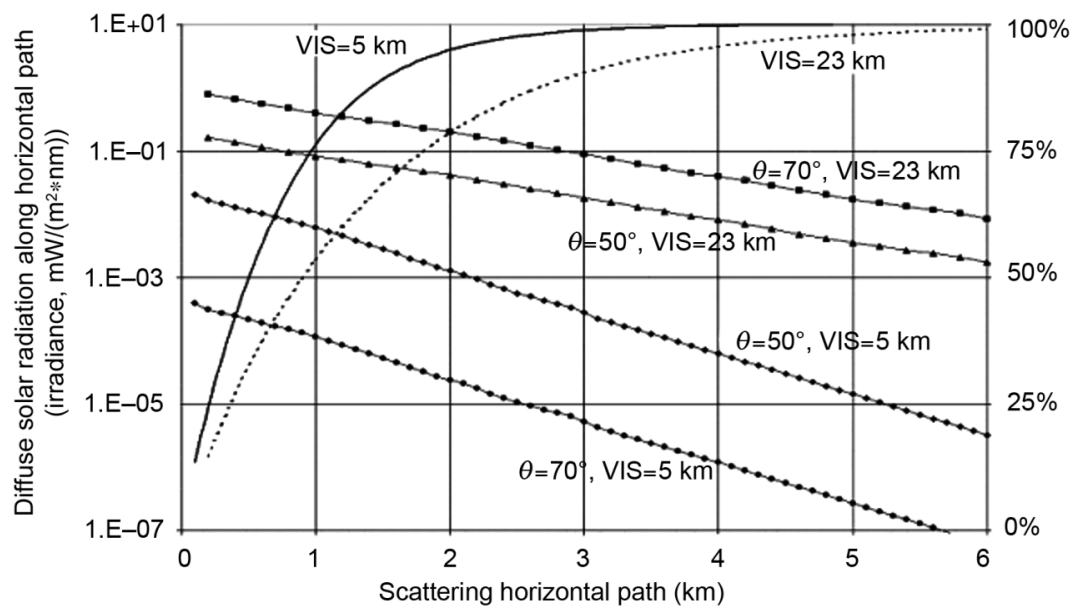

Fig. 6. Computed intensity of diffuse solar radiation collected along a horizontal path, as function of the scattering distance from the instrument. Four curves are plotted for different SZA and visibility values, considering $\lambda=330 \mathrm{~nm}$. The accumulated probability trends, respectively due to VIS $=23 \mathrm{~km}$ and to VIS $=5 \mathrm{~km}$ are also shown.

fuse solar radiation using DOAS lies, especial$1 y$, in the field of air pollution control and monitoring. It will also allow a more rapid use of DOAS instruments, operating in the UV/VIS region, in the new and expanding field of air pollution tomography.

The analytical methodology is quite similar to that employed in horizontal measurements in 
the stratosphere: the value of the given gas slant column is found from the difference between measurements of diffuse solar radiation along a «vertical» (or equivalent) path and those along a «horizontal» path. However, compared to ACILA, this method requires the derivation of an ATE which includes simulation of multiple scattering (Palazzi, 2003) and a knowledge, during measurement, of additional parameters such as, for example the spectral extinction coefficient of the atmosphere along the horizontal measurement path, which is related to the visibility during the measurement time. Figure 6 shows the results of calculations along a near-ground-level horizontal path for two different values both of SZA $\left(50^{\circ}\right.$ and $\left.70^{\circ}\right)$ and visibility (5 and $\left.23 \mathrm{~km}\right)$ for a wavelength of $330 \mathrm{~nm}$. It is interesting to observe that, when the visibility is known, one can obtain the integral of the given gas concentration along the horizontal measurement path.

\section{Conclusions}

The use of DOAS for the measurement of trace gases in the atmosphere is currently passing through a stage of rapid development. DOAS, as opposed to other remote sensing techniques, does not require absolute irradiance measurements since it exploits the differences in normalised radiation fluxes over the observed spectral region, thus allowing great flexibility and economy in making such measurements. DOAS measures the columnar abundances of trace gases such as: $\mathrm{NO}_{2}, \mathrm{SO}_{2}, \mathrm{O}_{3}, \mathrm{NO}_{3}, \mathrm{BrO}, \mathrm{OClO}$, $\mathrm{HNO}_{2}, \mathrm{CH}_{2} \mathrm{O}$, benzene, toluene and xylene. DOAS can also measure concentrations of the nitrate radical, $\mathrm{NO}_{3}$ and $\mathrm{OClO}$, which are not accessible using other techniques, as well as providing more accurate and reliable measurements of $\mathrm{OH}$ radicals, one of the main initiators of the chain of photochemical processes.

The development of inversion algorithms, applied to sets of DOAS measurements for the determination of concentration profiles of trace gases, increases the information content as well as its range of applications, including the important area of the validation of satellite data.

For these reasons, the interest in DOAS is shifting from climatic studies in the stratosphere to air quality control and monitoring. In fact, the high information content of DOAS measurements allows its use not only in air quality surveys or networks, but also in special investigations such as the interpretation of transport and dispersion processes, and the chemical transformations taking place within the PBL.

Because the installation of the spectrometer is relatively easy on board an aircraft, this system can be used to map atmospheric pollutants over large metropolitan areas. By flying at altitudes between 2000 and 4000 m, DOAS can detect the distribution of gas pollutant concentrations within the PBL.

To fully exploit the multiplicity and flexibility of DOAS methodology for air quality control and monitoring, the development of a set of measurement procedures, including atmospheric transmission models, to be applied according to the particular application, will be crucial.

This paper indicates the main areas of study necessary to bring on line the proposed methodologies, such as horizontal view looking or oblique-down view looking, which are both deduced from the classical configuration of measurement, i.e., the zenith-sky or vertical view looking approach. These new methodologies and their combined use under opportune conditions yields the 2D tomography of atmospheric trace gases. The information obtained by such kind of measurements will moreover be used to interpret the transport, dispersion and transformation of atmospheric pollutants in atmosphere, to obtain vertical profiles of pollutants in the lower troposphere (1-2 km) and to follow flux divergence within given areas (urban, industrial, etc.).

\section{Acknowledgements}

This work was supported by ASI, EU APEINFRA project. The author Daniele Bortoli was financially supported by the Subprograma Ciência e Tecnologia do $3^{\circ}$ Quadro Comunitário de Apoio.

\section{REFERENCES}

Brocco, D., R. Fratarcangeli, L. Lepore and I. VenTRONE (1992): Spettroscopia ad assorbimento ottico 
differenziale per la valutazione della qualità dell' aria in aree urbane, Acqua-Aria, 617-627.

Browell, E.V., S. Ismail and W.B. Grant (1998): Differential absorption LIDAR (DIAL) measurements from air and soace, Appl. Phys. Ser. B, 67, 399-410.

Carli, B., U. Cortesi, G. Redaelli, C. Blom and M. ChipPERFIELD (2000): Airborne Polar Experiment-Geophysica Aircraft In Antarctica (APE-GAIA), SPARC Newslett., 15, 21-24.

Edner, H., P. Ragnarson, S. SpÄnnare and S. Svanberg (1993): Differential optical absorption spectroscopy (DOAS) system for urban atmospheric pollution monitoring, Appl. Opt., 32 (3), 327-333.

Evangelisti, F., A. Baroncelli, P. Bonasoni, G. GioVANELLI and F. RAVEGNANI (1995): Differential optical absorption spectrometer for measurement of tropospheric pollutants, Appl. Opt., 34 (15), 2737-2744.

Finzi, G., G. Pirovano and M. Volta (2001): Gestione della Qualità dell'Aria. Modelli di Simulazione e Previsione (McGraw-Hill).

Giovanelli, G., T. TIRABAssi and S. SANDRoni (1979): Sulphur dioxide plume structure by mask correlation spectroscopy, Atmos. Environ., 13, 131-138.

Giovanelli, G., P. Bonasoni and F. Evangelisti (1990): $\mathrm{O} 3$ and NO 2 Ground-based measurements at Terra Nova Bay, Antarctica, in Proceedings of the Conference "Italian Research on Antarctic Atmosphere», edited by M. Colacino, G. Giovanelli and L. Stefanutti, SIF, Bologna, vol. 27, 255-268.

Giovanelli, G., A. Petritoli, U. Bonafè, D. Bortoli, I. Kostadinov and F. RAVEGNANI (2000): Stratospheric trace-gases measurements by GASCOD/A spectroradiometer during the Antarctic APE-GAIA campaign, in Quadrennial Ozone Symposium, 3-8 July, Sapporo, Japan.

Giovanelli, G., D. Bortoli, I. Kostadinov, A. Petritoli and F. RAVEGNANI (2001): Thin optical depth stratospheric gases detection with ground-based off-axis UVVIS spectrometer at Dome Concordia NDSC station, Polar Atmospheres - Scientific and Technical Report Series, 2, 47-53.

Hashmonay, R.A., M.G. Yost and Chang-Fu Wu (1999): Computed tomography of air pollutants using radial scanning path-integrated optical remote sensing, Atmos. Environ., 33, 267-274.

Kostadinov, I., G. Giovanelli, D. Bortoli, A. Petritoli, F. RaVEgnani and G. PACE (2006): A multi-input UVVIS airborne GASCOD/A $4 \pi$ spectroradiometer for the validation of satellite remote sensing measurements, Ann. Geophysics, 49 (1), 71-82 (this volume).
NoxON, J.F. (1975): Nitrogen dioxide in the stratosphere and troposphere measured by ground-based absorption spectroscopy, Science, 189, 547-549.

PAlazZi, E. (2003): Sviluppo di modelli a supporto della metodologia DOAS per la determinazione degli inquinanti in troposfera, Tesi di Laurea (Università degli Studi di Bologna).

Petritoli, A., G. Giovanelli, U. Bonafè, D. Bortoli, I. KostadinOV and F. RAVEGNANI (1999): An airborne UV and Visible spectrometer for DOAS and radiometric measurements, SPIE Proc., 3756, 544-554.

Petritoli, A., G. Giovanelli, I. Kostadinov, F. RavegNANi, D. Bortoli, P. Bonasoni, F. Evangelisti, U. Bonafè and F. CAlzolari (2002a): Tropospheric and stratospheric $\mathrm{NO}_{2}$ amount deduced by slant column measurements at Mt. Cimone station, Adv. Space Res., 29 (11), 1691-1695.

Petritoli, A., G. Giovanelli, F. Ravegnani, I. KostadiNOv, D. Bortoli and A. OUlanovsky (2002b): Off-axis measurements of atmospheric trace gases from airborne UV/VIS spectrometer, Appl. Opt., 41, 55935599.

Platt, U. and D. PERnER (1980): Direct measurements of atmospheric $\mathrm{CH}_{2} \mathrm{O}, \mathrm{O}_{3}, \mathrm{NO}_{2}$ and $\mathrm{SO}_{2}$ by differential optical absorption in the near UV, J. Geophys. Res., 85 (C10), 6329-6335.

Platt, U., D. Perner, G.W. Harris, A.M. Winer and J.N. PITTS JR. (1980): Observation of nitrous acid in an urban atmosphere by differential optical absorption, $\mathrm{Na}$ ture, 285, 312-314.

Platt, U., D. Perner, J. Schroeder, C. Kessler and A. ToENNISEN (1981): The diurnal variation of $\mathrm{NO}_{3}, J$. Geophys. Res., 86, 965-970.

Ravegnani, F., F. Evangelisti, A. Baroncelli, P. Bonasoni, G. Giovanelli and I. Kostadinov (1997): Measurement of atmospheric polluttants by a DOAS spectrometer in urban areas, SPIE Proc., 3106, 179-186.

Solomon, S., A.L. Schemeltekipf and E.W. SANDER (1987): On the interpretation of zenith sky absorption measurements, J. Geophys. Rev., 92, 8311-8325.

Vogel, B., U. Corsmeier, H. Vogel, F. Fiedler, J. KÜHLWEIN, R. Friedrich, A. OBERMEIER, J. WePPNER, N. KALthoff, D. BÄUmer, A. Bitzer and K. JAY (2000): Comparison of measured and calculated motorway emission data, Atmos. Environ., 34 (15), 2437-2450.

von Kuhlmann, R., M.G. Lawrence, P.J. Crutzen and P.J. RAsCH (2003): A model for studies of tropospheric ozone and nonmethane hydrocarbons: model evaluation of ozone-related species, J. Geophys. Res., 108 (D23), 4729-4755. 